\title{
DIFFUSION MECHANISMS IN THE CU/Sb THIN FILM SYSTEM
}

\author{
R. HALIMI and A. MERABET* \\ Département de Physique du solide, Institut de Physique, Université de \\ Constantine, Constantine, Algêrie \\ * I.N.E.S. d'optique et de Mécanique de précision, Sétif, Algérie
}

\begin{abstract}
Résumé - L'interdiffusion dans les films minces bimétalliques de Cu/Sb est étudiée par rétrodiffusion Rutherford dans l'intervalle de température $150-300^{\circ} \mathrm{C}$. Les profils de diffusion sont analysés à l'aide du modèle de Whipple. Les valeurs des coefficients de diffusion en volume de $\mathrm{Sb}$ dans $\mathrm{Cu}$ étant prises de la référence/12/, on trouve les energies d'activation de diffusion par les joints de grains suivantes: 1,12 eV et 1,26 eV pour les échantillons respectivement, ( $600 \AA$ Sb sur $650 \AA \mathrm{Cu})$ et (1800 $\AA$ Sb sur $3100 \AA$ Cu). Il est établi que les coefficients de diffusion par les joints de grains sont $13^{\circ}-10^{6}$ fois plus importants que ceux de la diffusion en volume extrapolés à partir des mesures de radiotraceur sur des échantillons massifs. Il est également observé que la diffusion est moins rapide dans les échantillons relativement épais.
\end{abstract}

\begin{abstract}
The interdiffusion of bimetallic Cu/Sb thin film couples is studied using Rutherford backscattering for annealing temperatures in the range $150-300^{\circ} \mathrm{C}$. Depth profiles are analyzed using the Whipple's model. Taking the lattice diffusivities of $\mathrm{Sb}$ in $\mathrm{Cu}$ from Ref./12/, following activation energies for grain boundary diffusion are found : $1,12 \mathrm{eV}$ and $1,26 \mathrm{eV}$ for respectively ( $600 \AA \mathrm{Sb}$ on $650 \AA \mathrm{Cu}$ ) and (1800 $\AA \mathrm{Sb}$ on $3100 \AA \mathrm{Cu})$ samples. It is established that the grain boundary diffusivities are $3-6$ times larger than the lattice diffusivities predicted by an extrapolation of radioactive tracer measurements of bulk specimens. It is also observed that diffusion is lower in relatively thick samples.
\end{abstract}

\section{1 - INTRODUCTION}

Interdiffusion in thin film couples has attracted considerable attention because of the importance of thin films in microelectronic devices /1 - 3/. Understanding the diffusion processes is also very important in such areas of investigation as crystallization, precipitation, oxydation and surface segregation in alloys etc. It is known that diffusion occurs much faster in thin solid films than in bulk materials since the presence of point and line defects, grain boundaries and strains can enhance the diffusion processes. It is for this reason that diffusion in thin films can be observed at temperatures well below those at which equilibrium vacancies diffusion is negligible. Other factors which can influence the diffusion in thin films are detailed by Weaver $/ 4 /$ and Balluffi and Blakely $/ 5 /$.

Diffusion measurements with thin films require high depth resolution due to the small film thickness and relatively short diffusion lengths at the temperatures of interest. Generally, analytical techniques such as Auger electron spectroscopy (AES) $/ 6 /$, secondary ion mass spectrometry (SIMS) /7/ and Rutherford backscattering spectroscopy (RBS) /8,9/ are applied to such studies.

The objective of this study is to determine grain boundary diffusion parameters in $\mathrm{Cu} / \mathrm{Sb}$ thin films using the RBS technique.

\section{2 - EXPERIMENTAL PROCEDURE}

The thin film couples are prepared by thermal evaporation in vacuum (10 6 Torr) of pure $(99,99 \%) \mathrm{Cu}$ and $\mathrm{Sb}$ metals. Copper films are deposited onto glass substrates at $350^{\circ} \mathrm{C}$ and 
then antimony films are deposited onto copper at $60^{\circ} \mathrm{C}$. The two evaporation have been performed without breaking the vacuum. Two sets of samples are evaporated : (600 $\AA \mathrm{Sb}$ on $650 \AA \mathrm{Cu}$ ) for the first set and (1800 $\AA$ Sb on $3100 \AA \mathrm{Cu})$ for the second. The film couples are annealed at $150-300^{\circ} \mathrm{C}$ in vacuum $\left(5.10^{-6}\right.$ Torr $)$.

Analysis of the samples was performed with Rutherford backscattering spectrometry. In the experiment, $\mathrm{He}^{+}$ions with energy $1,4 \mathrm{MeV}$ collimating through a slit system are allowed to hit normally the specimen surface. The detector forms an angle of $170^{\circ}$ with respect to the incident direction. The detector signals are converted into an energy spectrum of the backscattered ions. The concentration profiles are computed from the energy spectra.

Grain size measurements and electron diffraction patterns are obtained using a $200 \mathrm{keV}$ transmission electron microscope and have been described elsewhere /10/.

\section{3 - EXPERIMENTAL RESULTS AND DISCUSSION}

Antimony diffusion in single-crystal copper was studied by the radioactive-tracer technique $111-13 /$. However in thin solid films, only one study has been realized using $x$-ray diffraction/10/.

Figure 1 shows energy backscattering spectra obtained from double layer films of $1800 \AA \mathrm{Sb}$ and $3100 \AA \mathrm{Cu}$ before and after annealing at various temperatures. The salient feature of this figure is immediately obvious from inspection of the spectra. There is no interdiffusion between the $\mathrm{Sb}$ and $\mathrm{Cu}$ films in an unannealed state, since the corresponding $\operatorname{spectrum}\left(\mathrm{F}_{i g} \cdot 1(1)\right)$ consists of two very distinct parts : the Sb spectrum on the higher-energy side and the Cu one in the lower-energy side. Annealing of samples at temperatures from 150 to $300^{\circ} \mathrm{C}$ increases significantly the interdiffusion (Fig. $1(2,3,4)$ for example).

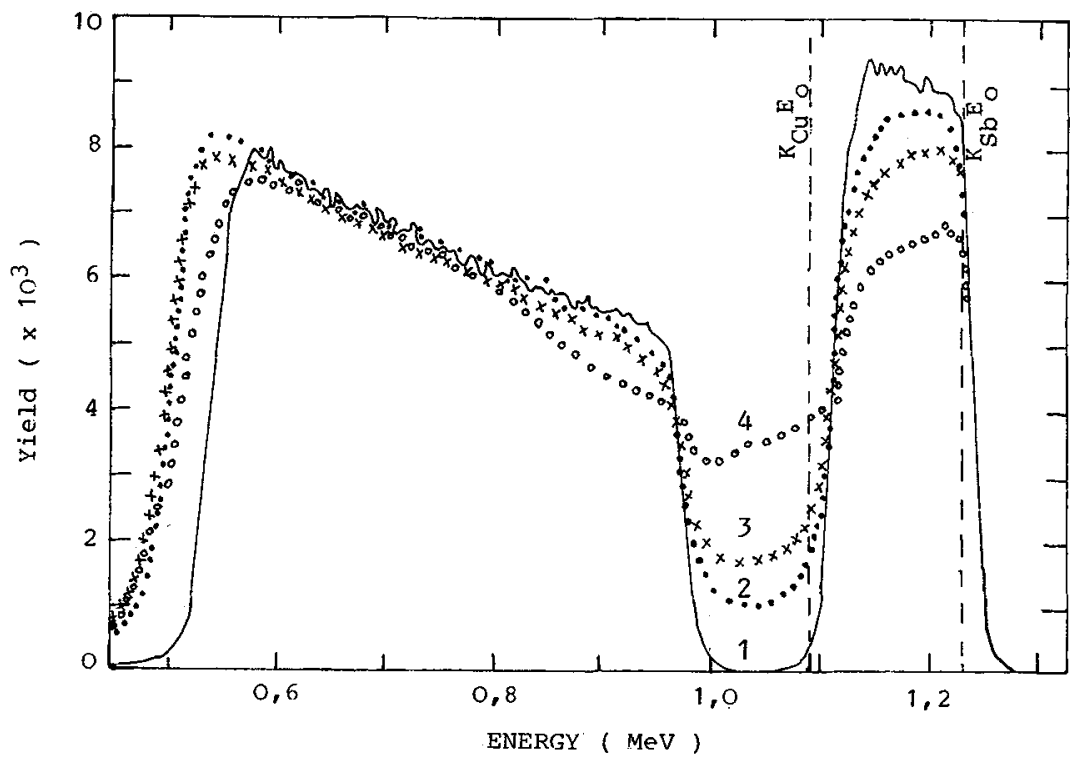

Fig.1 - Rutherford backscattering energy spectra from $1800 \AA$ Sb on $3100 \AA$ Cu samples subjected to various stages of annealing: (1) as-evaporated, (2) after $230 \mathrm{~min}$ at $150^{\circ} \mathrm{C}$, (3) after $195 \mathrm{~min}$ at $200^{\circ} \mathrm{C}$ and (4) after $130 \mathrm{~min}$ at $250^{\circ} \mathrm{C}$.

In order to examine the diffusion of $\mathrm{Sb}$ in $\mathrm{Cu}$ thin films, we have used spectra such as those in fig. 1 to construct the diffusion profiles. Some of the depth profiles for the second set of samples before and after annealing are shown in, Fig. 2. Profile broadenings at the interfaces due to diffusion are clearly evident. In many cases, long diffusion "tails" of nearly 
constant concentration of $\mathrm{Sb}$ into the $\mathrm{Cu}$ underlayers are observed. These"tails" are related to grain boundary diffusion.

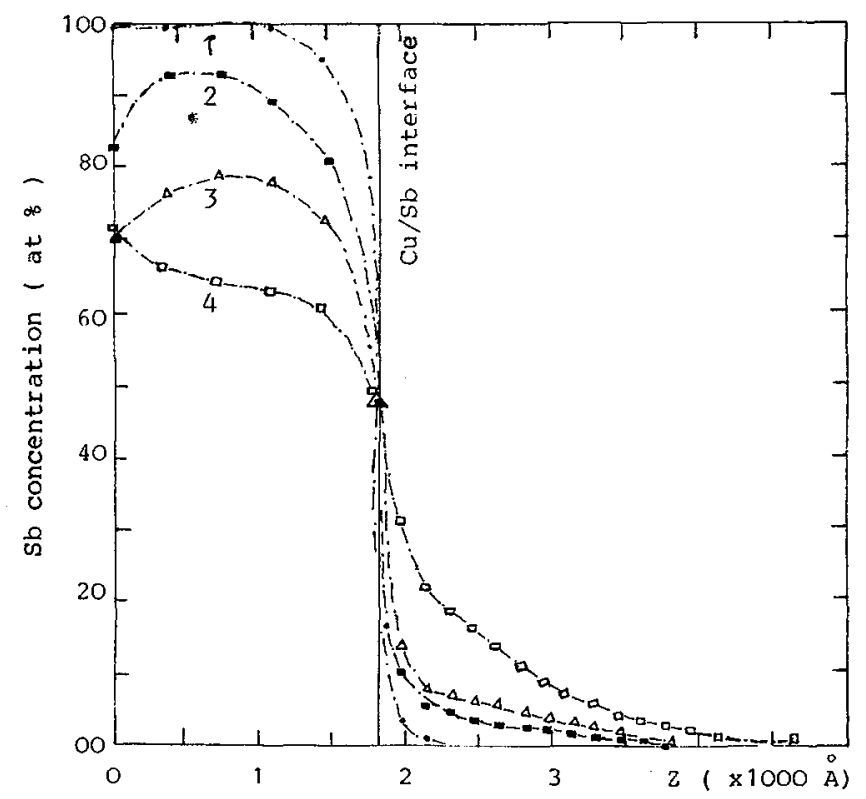

Fig. 2 - Diffusion profiles for Sb in Cu thin films from the data of Fig. 1.

Interdiffusion in thin films has most readily been understood in terms of whipple's theory of diffusion $/ 14 /$, in which grain boundary diffusion is separated from bulk diffusion. The grain boundary diffusion parameters can be determined by using Whipple's solution of the grain boundary problem with semi-infinite solid boundary conditions, assuming that the diffusion coefficients are independent of concentration and that diffusion in the grain boundaries $\left(D_{b}\right)$ is much faster than direct diffusion through the grain $\left(D_{1}\right)$.

According to Le Claire $/ 15 /$, grain boundary diffusivities, $\mathrm{D}_{b}$, can be calculated from the following equation :

$$
\delta D_{b}=0,66\left(\partial \ln \bar{C} / \partial z^{6 / 5}\right)^{-5 / 3}\left(4 D_{1} / t\right)^{1 / 2}
$$

where $\bar{C}$ is the Sb concentration averaged at the depth of $z$ from the original Cu/Sb interface, $t$ is the diffusion annealing time and $\delta$ is the grain boundary width. This equation shows that a plat of $\ln \bar{C}$ as a function of $z^{6 / 5}$ is a straight line whose slope determines $\delta D_{b}$ we confine ourselves on the data for $\mathrm{Sb}$ diffusing into the $\mathrm{Cu}$ underlayer, i.e, the $\mathrm{Cu}$ side of the depth profiles. Some typical plots of in $\mathrm{C}$ versus $z^{6 / 5}$ are shown in Fig. 3 .

$\delta D_{h}$ can then be obtained from the slopes of "Whipple" plots taken in the diffusion "tail" region. The calculated values of $D_{b}$ at various temperatures, taking the bulk diffusivities obtained at higher temperatures $\mathrm{from} / 12 /$ and extrapolated to our temperature range and assuming $\delta$ of $10 \AA$, are presented in table 1 and shown in Fig. 4. If we assume an Arrhenius temperature dependence, the grain boundary activation energies are : $1,12 \mathrm{eV}$ for $600 \AA \mathrm{Sb}$ on $650 \AA \mathrm{Cu}$ samples and $1,26 \mathrm{eV}$ for $1800 \AA \mathrm{Sb}$ on $3100 \AA \mathrm{Cu}$ specimens.

According to the $\mathrm{Cu} / \mathrm{Sb}$ equilibrium phase diagram $/ 16 /$, there are two stable intermetallic compounds ( $\mathrm{Cu}_{2} \mathrm{Sb}$ and $\mathrm{Cu}_{9} \mathrm{Sb}_{2}$ ) in the considered temperature range. The solid solubility of $\mathrm{Sb}$ in $\mathrm{Cu}$ is about 3 at $\%$ at $300^{\circ} \mathrm{C}$ and 1,5 at $\%$ at $250^{\circ} \mathrm{C}$. The grain boundary diffusion coefficients of $\mathrm{Sb}$ in $\mathrm{Cu}$ are determined for short periodes of heat treatment such that the solid reaction between the two previous metallic films did not occur. Indeed, it has been found that, depending of the annealing temperature, the reaction was clearly produced after a certain annealing time of samples. To get an idea, the reaction was observed after about 
10 min of annealing at $300^{\circ} \mathrm{C}$ of $600 \AA \mathrm{Sb}$ on $650 \AA \mathrm{Cu}$ sample, yielding to the formation and growth of the $\mathrm{Cu}_{2} \mathrm{Sb}$ phase /17/. Therefore, the decrease (respectively increase) of $\mathrm{Sb}$ concentration in the 56 (respectively $\mathrm{Cu}$ ) film, (Fig. 2, plateau of profile 4), could be attributed to the $\mathrm{Cu}_{2} \mathrm{Sb}$ phase formation.

It is worth noting that the grain boundary diffusivities values measured here for $S b$ diffusion in $\mathrm{Cu}$ thin films are 3-6 times larger than the lattice diffusivities predicted from bulk measurements. The activation energies for the grain boundary diffusion in thin films are substantially lower than that for the volume diffusion (1,9 eV). This result confirms that thermal processes in thin films require temperatures lower that those necessary for the same reaction in a bulk sample, suggesting a grain boundary diffusion mechanism as the dominant process.

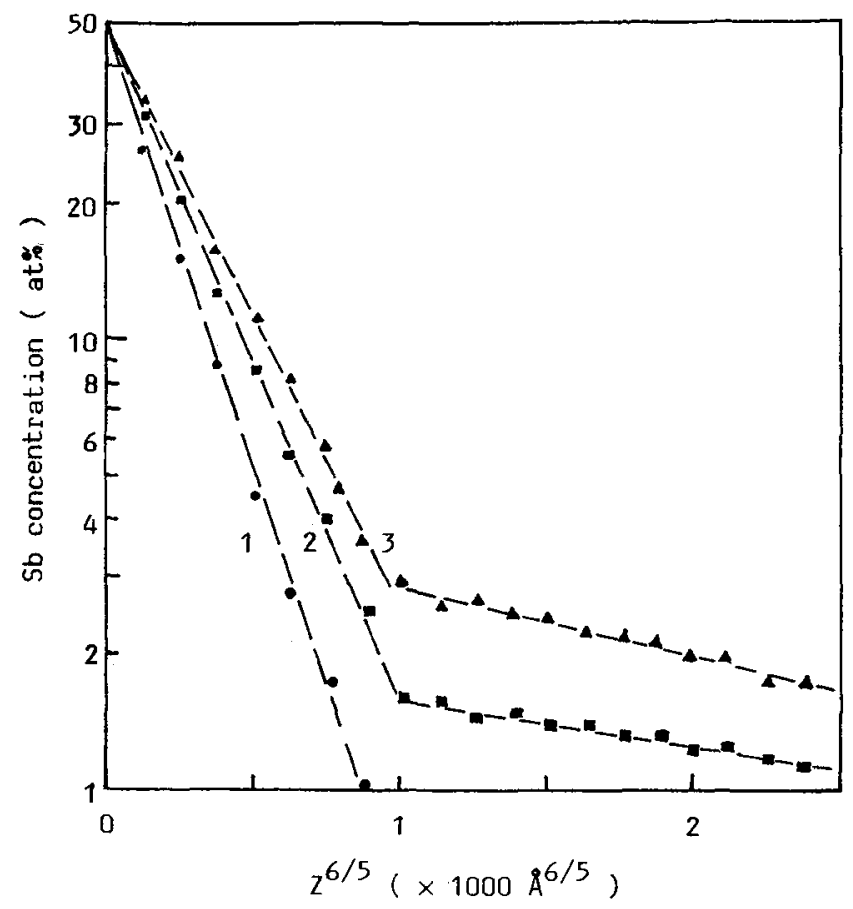

Fig. 3 - Whipple plot In $\bar{C}$ versus $z^{6 / 5}$ for $600 \AA$ Sb on $650 \AA \mathrm{Cu}$ samples : (1) as-deposited, (2) annealed at $250^{\circ} \mathrm{C}$ for $10 \mathrm{~min}$ and (3) $300^{\circ} \mathrm{C}$ for $5 \mathrm{~min}$.

Table 1. Grain boundary diffusion parameters of Sb in $\mathrm{Cu}$ thin films

\begin{tabular}{lcccc}
\hline Sample & Temperature $\left({ }^{\circ} \mathrm{C}\right)$ & $D_{b}\left(\mathrm{~cm}^{2} / \mathrm{s}\right)$ & $D_{b}^{0}\left(\mathrm{~cm}^{2} / \mathrm{s}\right)$ & $E_{b}(\mathrm{eV})$ \\
\hline & 150 & $3,66 \cdot 10^{-17}$ & & \\
First set & 200 & $8,36 \cdot 10^{-16}$ & $7,46.10^{-4}$ & $1,12 \pm 0,01$ \\
$d(\mathrm{Cu})=650 \AA$ & 250 & $1,16 \cdot 10^{-14}$ & & \\
$d(S b)=600 \AA$ & 300 & $1,01 \cdot 10^{-13}$ & & \\
\hline
\end{tabular}




$\begin{array}{lllll}\text { Second set } & 150 & 3,25 \cdot 10^{-18} & & \\ d(C u)=3100 \AA & 200 & 1,22 \cdot 10^{-16} & 3,01 \cdot 10^{-3} & 1,26 \pm 0,04 \\ d(S b)=1800 \AA & 250 & 1,66 \cdot 10^{-15} & & \\ & 300 & 2,74 \cdot 10^{-14} & & \end{array}$

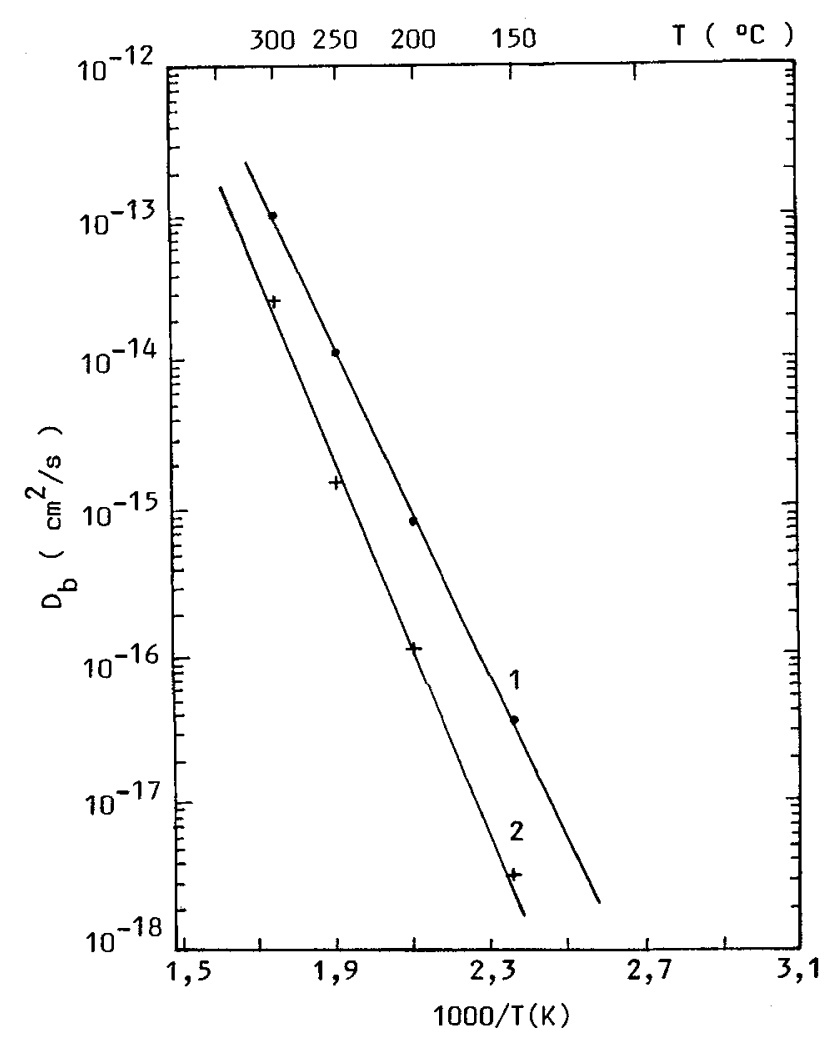

Fig. 4 - An Arrhenius plot of the measured $D_{b}$ values for $S b$ diffusion in $C u$ thin films: (1) first set and (2) second set of samples.

It is also observed that the diffusion in thinner samples ( the first set) occurs more rapidly than in the relatively thicker samples (the second set). Indeed, the grain boundary diffusivities in the first case are about one order of magnitude larger and the activation energy is lower than the one in the second case. This feature is probably due to the grain structure of the films. The as-deposited Cu grains have an average grain size of about $1000 \AA$ and $3000 \AA$ respectively for the first and the second set of samples. On annealing, no significant grain growth is remarked.

It is interesting to underline that the value $(1,26 \mathrm{eV})$ of the grain boundary activation energy for the second set of samples, is in agreement with the value $(1,28 \mathrm{eV})$ found from $X$-ray diffraction measurements on ( $2000 \AA$ Sb evaporated on $2700 \AA \mathrm{Cu}$ ) samples /10\%. The analysis technique used in $/ 10$ / did not distinguish between grain boundary and lattice diffusion, however, it is believed that the activation energy represents the grain boundary diffusion.

\section{ACKNOWLEDGEMENT}

The authors wish to thank Dr. F. Schwabe ( C.I.B.A.S., Freidrish - Schiller University, Jena, G.D.R ) for RBS measurements. 


\section{REFERENCES}

/1/ Poate, J.M., Tu, K.N. and Mayer, J.W., Thin Films - Interdiffusion and Beactions (WileyInterscience, New York) 1978.

/2/ Hall, P.M. and Morabito, J.M., Thin Solid Films 53 ( 1978 ) 175.

/3/ Tu, K.N., Ann. Rev. Mater. Sci. 15 (1985) 147.

14/ Weaver, C., in Physics of Thin Films, vol.6, M.H. Francombe and R.W. Hoffmann (Academic Press, New York ) 1971 , p. 301.

/5/ Balluffi, R.W. and Blakely, J.M., Thin Solid Films 25 (1975) 363.

/6/ Hall, 'P.M., Morabito, J.M. and Panousis, N.T., Thin Solid Films 41 (1977) 341.

/7/ Dorner, P., Gust, W., Predel, B., Roll, U., lodding, A. and Odelius, H., Philos. Mag. 49 (1984) 557 .

/8/ Compisano, S.U., Costanzo, E. and Rimini, E., Philos. Mag. 35 (1977) 1333.

19/ Schoen, J.M., Poate, J.M., Doherty, C.J. and Melliar-Smith, C.M., J. Appl. Phys. 50 (1979) 6910.

/10/ Halimi, R., Thesis of Ph.D., Minsk, URSS, 1984.

/11/ Inman, M.C., Barr, L.W., Acta Met. 8 (1960) 122.

/12/ Gorbatchev, V.A., Klotsman, 5.M., Rabovski, Ya.A., Talinski, V.K. and Timofeev, A.N., Fiz. Metal. i Metalloved. 35 (1973) 889.

/13/ Krautheim, G., Neidhart, A. and Reinhold, U., Solid State Commun. 34 (1980) 163.

/14/ Whipple, R.T.P., Philos. Mag. 45 (1954) 1225.

/15/Le Claire, A.D., Brit. J. Appl. Phys. 14 (1963) 351.

$/ 16 / \mathrm{N}$. Kh. Abricossov, Binary and Multicomponent Systems on Copper Base ( Metallurgia, Moscow, 1979).

/17/R. Halimi and A. Merabet, Surface Sci., (in press). 